\title{
Development of the PROMIS-based Research Assessment and Clinical Tool-Fatigue (ReACT-F)
}

\author{
Kristin A. Dickinson ${ }^{1,2}$ (D) $\cdot$ Debra Lynch Kelly ${ }^{3} \cdot$ Jin-Shei Lai $^{4} \cdot$ Leorey N. Saligan ${ }^{2}$
}

Received: 29 August 2018 / Accepted: 11 December 2018 / Published online: 11 January 2019

(C) The Author(s) 2019

\begin{abstract}
Purpose Evidence has shown that cancer-related fatigue (CRF) may be a treatment-limiting symptom and often impairs healthrelated quality of life. Accurate assessment of the multidimensional nature of CRF could help drive interventions to mitigate this debilitating symptom. Currently, there are no clinical tools to effectively and efficiently assess the multidimensionality of CRF. The purpose of this paper is to introduce a CRF-specific short form that can assess the multidimensional nature of CRF for use in the clinical setting.

Methods The CRF-specific short form was developed using the 95-item PROMIS® fatigue bank. Bi-factor analysis was used to evaluate dimensionality of the alternative model using fatigue for the general factor and physical, cognitive, affective, global, and motivational for the local factors. After unidimensionality was confirmed (loading factor $>0.3$ ), one item from each local factor was selected using discrimination power for inclusion in the CRF-specific short form.

Results The Research Assessment and Clinical Tool-Fatigue (ReACT-F) was created from the 95-item PROMIS fatigue bank using established item parameters. The ReACT-F assesses five common dimensions of CRF as well as perceived burden of the fatigue dimensions.

Conclusions The ReACT-F is a CRF-specific self-report short form that addresses the need for a brief, clinically useful tool to quickly assess the multidimensional nature of CRF. We anticipate that the ReACT-F can be completed in the clinical setting in approximately 3 minutes, providing clinicians with meaningful data to drive personalized interventions. Further validation of the ReACT-F is highly encouraged.
\end{abstract}

Keywords Fatigue $\cdot$ Cancer $\cdot$ Psychometrics $\cdot$ Questionnaire design

\section{Introduction}

Cancer-related fatigue (CRF) is a highly prevalent, complex, multidimensional symptom that can greatly impair the healthrelated quality of life of cancer patients [1,2]. Clinical guidelines have adopted a single-item, 0 to 10 numeric rating scale

Kristin A. Dickinson

kristin.dickinson@unmc.edu

1 College of Nursing, University of Nebraska Medical Center, 985330 Nebraska Medical Center, Omaha, NE 68198-5330, USA

2 National Institute of Nursing Research, National Institutes of Health, Bethesda, MD, USA

3 College of Nursing, University of Florida, Gainesville, FL, USA

4 Feinberg School of Medicine, Northwestern University, Chicago, IL, USA to initially screen for CRF due to its easily administered nature [3-6]. Several guidelines recommend a more comprehensive evaluation when patients rate their fatigue $\geq 4$ (i.e., moderate fatigue) using a $0-10$ numerical rating scale. This evaluation includes a focused history, assessment of treatable contributing factors (anemia, nutrition deficits, pathologic/physiologic abnormalities, etc.), and concurrent symptoms (pain, depression, sleep disturbance, etc.) and conditions (cardiac, renal, pulmonary, etc.) [3-6]. Moreover, inclusion of a measure of the multidimensional nature of CRF would be advantageous to understand the full fatigue experience of cancer patients.

The fatigue experienced by cancer patients is often reported to be multidimensional in nature including physical, emotional, and cognitive dimensions, although the exact terminology for each dimension can vary (i.e., affective, motivational, behavioral, functional, etc.) $[7,8]$. Therefore, when conducting an in-depth evaluation of CRF, clinicians should consider the multidimensional nature of CRF to fully capture the CRF 
experience and optimize management. Consistent with the Precision Medicine Initiative of the National Institutes of Health (NIH), understanding the specific dimension of CRF that most affects the patient can help guide the clinician to develop a more tailored and personalized management strategy.

Though comprehensive multidimensional fatigue assessments are available (e.g., revised Piper Fatigue Scale, Multidimensional Fatigue Inventory, and the Fatigue Questionnaire), most of them were developed using classical test theory resulting in measures that may not be best suited for a clinical environment [9]. Applications from the PROMIS ${ }^{\circledR}$ (Patient-Reported Outcomes Measurement Information System, http:// www.healthmeasures.net) fatigue item bank are expected to overcome these limitations [10]. As part of the NIH's roadmap project, the PROMIS® was developed to offer a set of person-centered measures to evaluate symptoms of individuals with or without chronic conditions [11]. One of these measures is the PROMIS instrument that assesses fatigue and the impact of fatigue on daily living [10]. The PROMIS fatigue bank consists of 95 items generated from a comprehensive literature review, focus groups, and individual interviews which were then calibrated using item response theory (IRT) models [10, 12], allowing for briefyet-precise fatigue estimation via tailored, individualized computer adaptive test (CAT), or short forms with fixed numbers of items. For the latter, multiple short forms can be created to meet users' needs and scores from these short forms are comparable as long as scores are generated using item parameters established in the original calibrated item banks. Yet precision levels may vary as demonstrated in Lai et al. (2011) in which three short forms were developed targeting patients with mild fatigue, severe fatigue, and for fatigue across the whole severity continuum. Several short forms derived from the PROMIS fatigue item bank are available [13-15], yet none of them target fatigue content areas that are important to cancer patients. Therefore, to fill this void, a content-specific CRF short-form was developed that can be used in the clinical setting.

\section{Methods}

Fatigue dimensions To determine the fatigue dimensions of interest, current multidimensional fatigue assessments were reviewed (Table 1) [16-21]. The most commonly assessed fatigue dimension was physical (20/20) followed by cognitive (16/20), affective (7/20), global (6/20), and motivational $(5 / 20)$. Thus, these five dimensions were selected moving forward. The physical dimension of CRF was conceptualized as fatigue related to energy level. The cognitive dimension of
CRF was conceptualized as fatigue related to thought processes, memory, and executive function. The affective dimension of CRF was conceptualized as fatigue related to emotions or feelings. The global dimension of CRF was conceptualized as encompassing the subjective experience of fatigue. Lastly, the motivational dimension of CRF was conceptualized as fatigue related to actions that maintain a meaningful or purposeful existence.

Assigning PROMIS fatigue items All 95 items in the PROMIS fatigue item bank were reviewed by the primary author (KD), who then assigned them to one of the five dimensions. This classification was then reviewed by the second author (DLK) for consensus. If there was disagreement with any classification, a third reviewer (LS) was included to achieve consensus.

\section{Statistical analysis}

The current PROMIS fatigue item bank was modeled to have one general fatigue factor with two local factors (experiences and impacts), which was psychometrically proven to be sufficiently unidimensional [10]. For this paper, in order to develop a content-specific CRF short form that produces scores comparable to the PROMIS fatigue item bank and its short forms, we first evaluated the sufficient dimensionality of the alternative model as discussed above using bi-factor analysis.

Bi-factor analysis includes two classes of factors: a general factor, defined by loadings from all of the items in the scale, and local factors, defined by loadings from pre-specified groups of items related to that sub-domain [22-25]. Items are considered sufficiently unidimensional when standardized loadings are $>0.3$ for all the items on the general factor. Similarly, if the loadings of all the items on a local factor are salient, this would indicate that the local factor is well defined even in the presence of the general factor, and it is more appropriate to report scores of local factors separately [22, 24, 26].

In the model used by the current study, the general factor was "fatigue" and the 5 local factors were physical, cognitive, affective, global, and motivational. Once sufficient unidimensionality was supported, we then created a content-specific CRF short form by selecting items from each local factor by reviewing item content, as well as using item parameter threshold values obtained from item response theory (IRT) estimation, particularly the discrimination parameter.

Discrimination power describes the strength of an item's discrimination between people at different fatigue levels below and above the threshold, indicating the degree of association between item responses and the fatigue latent trait. Items with the highest discrimination parameters typically produce 
Table 1 Multidimensional instruments for assessing fatigue domains

Fatigue dimension

\begin{tabular}{|c|c|c|c|c|c|c|c|}
\hline & \multirow[b]{2}{*}{$\begin{array}{l}\text { General } \\
\text { Global } \\
\text { Perception } \\
\text { Fatigue } \\
\text { Subjective } \\
\text { Experience }\end{array}$} & & & & & & \\
\hline & & $\begin{array}{l}\text { Physical } \\
\text { Activity } \\
\text { Somatic } \\
\text { Motor Energy } \\
\text { Sensory } \\
\text { Vigor }\end{array}$ & $\begin{array}{l}\text { Cognitive } \\
\text { Mental } \\
\text { Concentration }\end{array}$ & Psychosocial & $\begin{array}{l}\text { Motivation } \\
\text { Behavioral } \\
\mathrm{T} \text { a s k } \\
\text { Avoidance }\end{array}$ & $\begin{array}{l}\text { Affective } \\
\text { Emotional }\end{array}$ & Other \\
\hline $\begin{array}{l}\text { Bristol Rheumatoid Arthritis } \\
\text { Fatigue Multidimensional } \\
\text { Questionnaire }\end{array}$ & & $\mathrm{x}$ & $\mathrm{x}$ & & & $\mathrm{x}$ & Living with Fatigue \\
\hline Cancer Fatigue Scale & & $\mathrm{x}$ & $\mathrm{x}$ & & & $\mathrm{x}$ & \\
\hline Checklist of Individual Strength & $\mathrm{x}$ & $\mathrm{x}$ & $\mathrm{x}$ & & $\mathrm{x}$ & & \\
\hline FACES & $\mathrm{x}$ & $\mathrm{x}$ & & & & & $\begin{array}{l}\text { Consciousness } \\
\text { Energized } \\
\text { Sleepiness }\end{array}$ \\
\hline Fatigue Impact Scale & & $\mathrm{x}$ & $\mathrm{x}$ & $\mathrm{x}$ & & & \\
\hline Modified Fatigue Impact Scale & & $\mathrm{x}$ & $\mathrm{x}$ & $\mathrm{x}$ & & & \\
\hline $\begin{array}{l}\text { Fatigue Scale for Motor and } \\
\text { Cognitive Functions }\end{array}$ & & $\mathrm{x}$ & $\mathrm{x}$ & & & & \\
\hline Fatigue Questionnaire* & & $\mathrm{x}$ & $\mathrm{x}$ & & & & \\
\hline $\begin{array}{l}\text { Multidimensional Fatigue } \\
\text { Inventory }\end{array}$ & $\mathrm{x}$ & $\mathrm{x}(2)$ & $\mathrm{x}$ & & $\mathrm{x}$ & & \\
\hline $\begin{array}{l}\text { Multidimensional Fatigue } \\
\text { Symptom Inventory (MFSI) }\end{array}$ & $\mathrm{x}$ & $\mathrm{x}(2)$ & $\mathrm{x}$ & & $\mathrm{x}$ & $\mathrm{x}$ & $\begin{array}{l}\text { Rationally vs } \\
\text { Empirically } \\
\text { derived subscales }\end{array}$ \\
\hline MFSI-SF & $\mathrm{x}$ & $\mathrm{x}(2)$ & $\mathrm{x}$ & & & $\mathrm{x}$ & \\
\hline Myasthenia Gravis Fatigue Scale & $\mathrm{x}$ & $\mathrm{x}$ & & & $\mathrm{x}$ & & \\
\hline Neurological Fatigue Index for MS & & $\mathrm{x}$ & $\mathrm{x}$ & & & & $\begin{array}{l}\text { Abnormal nocturnal } \\
\text { sleep, relief } \\
\text { by rest }\end{array}$ \\
\hline Profile of Fatigue & & $\mathrm{x}$ & $\mathrm{x}$ & & & & \\
\hline Revised Piper Fatigue Scale & & $\mathrm{x}$ & $\mathrm{x}$ & & $\mathrm{x}$ & $\mathrm{x}$ & \\
\hline Schwartz Cancer Fatigue Scale & & $\mathrm{x}$ & $\mathrm{x}$ & & & $\mathrm{x}$ & Temporal \\
\hline $\begin{array}{l}\text { Swedish Occupational Fatigue } \\
\text { Inventory }\end{array}$ & & $\mathrm{x}$ & & & $\mathrm{x}$ & & $\begin{array}{l}\text { Sleepiness, physical } \\
\text { exertion, physica } \\
\text { discomfort }\end{array}$ \\
\hline $\begin{array}{l}\text { Visual Analogue Scale for } \\
\text { Fatigue }^{+}\end{array}$ & $\mathrm{x}$ & $\mathrm{x}$ & & & & & \\
\hline WEIMUS & & $\mathrm{x}$ & $\mathrm{x}$ & & & & \\
\hline Wu Cancer Fatigue Scale & & $\mathrm{x}$ & $\mathrm{x}$ & & & $\mathrm{x}$ & \\
\hline
\end{tabular}

*Synonymous names: Chalder Fatigue Scale, Fatigue Rating Scale, Fatigue Scale

${ }^{+}$Synonymous name: Lee Fatigue Scale

the highest information function (i.e., lowest measurement errors) were considered the best candidates to be included in the short form.

\section{Results}

The 95 items from the PROMIS fatigue bank were organized into the five fatigue dimensions (physical, cognitive, affective, global, and motivational) as listed in Table 2. After consensus was achieved, there were 12 items from the PROMIS fatigue bank that fit into the physical dimension, 13 in the cognitive dimension, 4 in the affective dimension, 32 for the global dimension, and 34 for the motivational dimension. Essential dimensionality of these items was supported with acceptable fit indices: RMSEA $=0.04, \mathrm{CFI}=0.985, \mathrm{TLI}=0.985$. All items showed higher loading to the general factor than to their 
Table 2 Organization of Items from the PROMIS Fatigue Bank into Five Fatigue Dimensions

\begin{tabular}{|c|c|c|c|c|}
\hline Physical & Cognitive & Affective & Global & Motivationa \\
\hline AN5 & FATIMP02 & AN15 & AN1 & AN3 \\
\hline FATEXP18 & FATIMP06 & FATEXP24 & AN2 & AN4 \\
\hline FATEXP19 & FATIMP11 & FATEXP26 & AN8 & AN7 \\
\hline FATEXP31 & FATIMP14 & FATEXP28 & FATEXP02 & AN12 \\
\hline FATEXP43 & FATIMP17 & & FATEXP05 & AN14 \\
\hline FATEXP44 & FATIMP20 & & FATEXP06 & AN16 \\
\hline FATEXP54 & FATIMP22 & & FATEXP07 & FATIMP01 \\
\hline FATIMP13 & FATIMP30 & & FATEXP12 & FATIMP03 \\
\hline FATIMP40 & FATIMP35 & & FATEXP13 & FATIMP04 \\
\hline FATIMP49 & FATIMP38 & & FATEXP16 & FATIMP05 \\
\hline FATIMP53 & FATIMP43 & & FATEXP20 & FATIMP08 \\
\hline \multirow[t]{23}{*}{ HI12 } & FATIMP44 & & FATEXP21 & FATIMP10 \\
\hline & FATIMP52 & & FATEXP22 & FATIMP16 \\
\hline & & & FATEXP29 & FATIMP15 \\
\hline & & & FATEXP34 & FATIMP18 \\
\hline & & & FATEXP35 & FATIMP19 \\
\hline & & & FATEXP36 & FATIMP21 \\
\hline & & & FATEXP38 & FATIMP24 \\
\hline & & & FATEXP40 & FATIMP25 \\
\hline & & & FATEXP41 & FATIMP26 \\
\hline & & & FATEXP42 & FATIMP27 \\
\hline & & & FATEXP45 & FATIMP28 \\
\hline & & & FATEXP46 & FATIMP29 \\
\hline & & & FATEXP48 & FATIMP34 \\
\hline & & & FATEXP49 & FATIMP36 \\
\hline & & & FATEXP50 & FATIMP37 \\
\hline & & & FATEXP51 & FATIMP42 \\
\hline & & & FATEXP52 & FATIMP45 \\
\hline & & & FATEXP56 & FATIMP47 \\
\hline & & & FATIMP09 & FATIMP48 \\
\hline & & & FATIMP33 & FATIMP51 \\
\hline & & & $\mathrm{HI} 7$ & FATIMP50 \\
\hline & & & & FATIMP55 \\
\hline & & & & FATIMP56 \\
\hline
\end{tabular}

own local factor indicating the existing PROMIS item parameters are valid on this alternative model. See Table 3 for a summary of the PROMIS item selection information.

The PROMIS-based Research Assessment and Clinical Tool-Fatigue (ReACT-F) CRF-specific short form was created using established item parameters (Fig. 1). Each item was selected based upon the discriminative value and is considered representative to each fatigue dimension. We added a numeric rating scale at the beginning of the questionnaire per the current fatigue assessment guidelines and we added an additional item, "Which aspect of fatigue is most bothersome to you" to assess the overall burden of the CRF dimensions and inform treatment decisions to optimize CRF management.

\section{Scoring}

This short form can be scored using similar approaches as used by other PROMIS fatigue short forms [27]. A 5-item questionnaire can only be scored when at least 4 of the items are completed. However, patients should be encouraged to complete all items to minimize measurement errors. Each question has a Likert scale with values ranging from one to five. A total raw score is calculated by summing the five items on the questionnaire and a prorated value will be used to replace missing value; therefore, the total score on the instrument ranges from 5 to 25 . Higher scores indicate worse fatigue. A raw score can then be translated into a PROMIS based $T$-score to create the final score for a respondent (details are shown in www.healthmeasures.net/score-and-interpret/ calculate-scores).

\section{Discussion}

The purpose of this paper was to develop a brief tool to capture the multidimensional nature of CRF. This was carried out by examining items included in the 95 -item PROMIS fatigue bank to determine if specific items could be selected to measure different fatigue dimensions. The final CRF assessment tool, the ReACT-F, consists of five PROMIS items, where each item is expected to screen a specific dimension of CRF: physical, cognitive, affective, global, and motivational.

The ReACT-F is a self-report short form that addresses the previously identified gap in the literature, which is the lack of a brief, clinically useful tool to quickly assess the multidimensional nature of fatigue in the cancer population. This new content-specific short form requires further validation to determine its clinical and scientific relevance. In the clinic, it is expected that the ReACT-F can aid clinicians to quickly assess the specific fatigue experience of their patients to allow for a more focused evaluation and tailored management. For example, patients reporting physical fatigue may be further evaluated for deconditioning, cardiopulmonary status, or musculoskeletal impairment, so physical rehabilitative strategies can be planned. Individuals who report affective fatigue may be referred for comprehensive psychological evaluation, while those who report affective fatigue or cognitive fatigue may benefit from occupational psychotherapy for behavioral adaptive coaching and a neuropsychology consult for comprehensive cognitive function evaluation, respectively.

Scientifically, this evaluation tool will be useful to determine the phenotypic characteristics of each fatigue dimension 
Table 3 PROMIS Item Selection Information

Item Item Stem $\quad$ Responses Scale* Discrimination

Physical Domain

Parameter Value

FATIMP49 To what degree did your fatigue interfere with your physical functioning?

FATEXP43 How physically drained were you on average?

FATEXP19 How often were you physically drained?

FATIMP13 How often were you too tired to do errands?

FATEXP18 How often did you run out of energy?

AN5 I have energy

HI12 I feel weak all over

FATIMP53 How often were you too tired to take a short walk?

FATEXP54 How often did you have physical energy?

FATEXP31 How often were you energetic?

FATEXP44 How energetic were you on average?

FATIMP40 How often did you have enough energy to exercise strenuously?

Cognitive Dimension

FATIMP20 How often did your fatigue make you feel less alert?

FATIMP17 How often did your fatigue make it difficult to make decisions?

FATIMP14 How often did your fatigue make it difficult to organize your thoughts when doing things at work (include work at home)?

FATIMP22 How often did your fatigue make it difficult to organize your thoughts when doing things at home?

FATIMP52 To what degree did your fatigue make you feel less alert?

FATIMP35 To what degree did your fatigue make it difficult to organize your thoughts when doing things at home?

FATIMP6 How often did your fatigue make you feel slowed down in your thinking?

FATIMP30 How often were you too tired to think clearly?

FATIMP43 To what degree did your fatigue make it difficult to organize your thoughts when doing things at work (include work at home)?

FATIMP2 To what degree did your fatigue make you feel slowed down in your thinking?

FATIMP38 To what degree did your fatigue make it difficult to make decisions?

FATIMP11 How often did your fatigue make you more forgetful?

FATIMP44 To what degree did your fatigue make you more forgetful?

4.02

3.81

3.65

3.51

3.39

2.71

2.69

2.41

2.23

2.11

1.98

1.17

2

2

3.33

2

2

3.26

3.17

2

3.13

3.11

1

3.09

2

2.97

2.97

2.92

2.86

2.81

2.71

2.36

Affective Dimension

AN15 I am frustrated by being too tired to do the things I want to do

3.90

FATEXP26 How often were you too tired to enjoy life?

FATEXP28 How often were you too tired to feel happy?

FATEXP24 How often did you have enough energy to enjoy the things you do for fun?

Global Dimension

FATEXP41 How run-down did you feel on average?

HI7 I feel fatigued

FATEXP35 How much were you bothered by your fatigue on average?

FATEXP40 How fatigued were you on average?

FATEXP22 How often were you bothered by your fatigue?

FATEXP34 How tired did you feel on average?

FATEXP36 How exhausted were you on average?

FATEXP51 How easily did you find yourself getting tired on average?

FATEXP56 What was the level of your fatigue on most days?

FATEXP48 How often did you find yourself getting tired easily?

FATIMP9 How often did your fatigue make it difficult to plan activities ahead of time?

FATEXP2 How often did you feel run-down?

FATEXP45 How sluggish were you on average?
3.19

3.04

2.11

4.32

4.32

4.23

4.18

3.90

3.87

3.83

3.71

3.62

3.51

3.48

3.42

3.39 
Table 3 (continued)

\begin{tabular}{|c|c|c|c|}
\hline Item & Item Stem & Responses Scale* & $\begin{array}{l}\text { Discrimination } \\
\text { Parameter Value }\end{array}$ \\
\hline FATEXP13 & How bushed were you on average? & 1 & 3.36 \\
\hline FATEXP52 & How wiped out were you on average? & 1 & 3.33 \\
\hline AN2 & I feel tired & 1 & 3.30 \\
\hline FATEXP7 & How often did you feel your fatigue was beyond your control? & 2 & 3.28 \\
\hline AN1 & I feel listless (“washed out”) & 1 & 3.27 \\
\hline FATEXP20 & How often did you feel tired? & 2 & 3.25 \\
\hline FATEXP29 & How often did you feel totally drained? & 2 & 3.09 \\
\hline FATIMP33 & How often did your fatigue limit you at work (include work at home)? & 2 & 3.09 \\
\hline FATEXP12 & To what degree did you feel tired even when you hadn't done anything? & 1 & 2.96 \\
\hline FATEXP38 & How fatigued were you on the day you felt most fatigued? & 1 & 2.92 \\
\hline FATEXP6 & How often did you feel tired even when you hadn’t done anything? & 2 & 2.84 \\
\hline FATEXP21 & How fatigued were you when your fatigue was at its worst? & 1 & 2.83 \\
\hline FATEXP49 & How often did you think about your fatigue? & 2 & 2.73 \\
\hline FATEXP5 & How often did you experience extreme exhaustion? & 2 & 2.66 \\
\hline FATEXP16 & How often were you sluggish? & 2 & 2.65 \\
\hline FATEXP50 & How fatigued were you on the day you felt least fatigued? & 1 & 1.91 \\
\hline AN8 & I need to sleep during the day & 1 & 1.64 \\
\hline FATEXP46 & On how many days was your fatigue worse in the morning? & 4 & 1.49 \\
\hline FATEXP42 & How much mental energy did you have on average? & 1 & 1.44 \\
\hline \multicolumn{4}{|c|}{ Motivational Dimension } \\
\hline FATIMP3 & How often did you have to push yourself to get things done because of your fatigue? & 2 & 4.77 \\
\hline AN3 & I have trouble $<\mathrm{U}>$ starting $</ \mathrm{U}>$ things because I am tired & 1 & 4.35 \\
\hline FATIMP1 & $\begin{array}{l}\text { To what degree did you have to push yourself to get things done because } \\
\text { of your fatigue? }\end{array}$ & 1 & 4.08 \\
\hline FATIMP50 & Did fatigue make you less effective at home? & 1 & 4.00 \\
\hline FATIMP16 & How often did you have trouble finishing things because of your fatigue? & 2 & 3.86 \\
\hline FATIMP27 & To what degree did you have trouble starting things because of your fatigue? & 1 & 3.82 \\
\hline FATIMP24 & How often did you have trouble starting things because of your fatigue? & 2 & 3.81 \\
\hline FATIMP48 & To what degree did your fatigue interfere with your social activities? & 1 & 3.81 \\
\hline FATIMP51 & To what degree did you have trouble finishing things because of your fatigue? & 1 & 3.80 \\
\hline FATIMP37 & Due to your fatigue were you less effective at work (include work at home)? & 1 & 3.79 \\
\hline FATIMP4 & How often did your fatigue interfere with your social activities? & 2 & 3.71 \\
\hline FATIMP10 & How often did your fatigue make it difficult to start anything new? & 2 & 3.71 \\
\hline FATIMP47 & $\begin{array}{l}\text { To what degree did you have to force yourself to get up and do } \\
\text { things because of your fatigue? }\end{array}$ & 1 & 3.68 \\
\hline FATIMP36 & To what degree did your fatigue make it difficult to start anything new? & 1 & 3.68 \\
\hline AN16 & I have to limit my social activity because I am tired & 1 & 3.61 \\
\hline FATIMP15 & $\begin{array}{l}\text { How often did your fatigue interfere with your ability to engage in } \\
\text { recreational activities? }\end{array}$ & 2 & 3.56 \\
\hline FATIMP18 & How often did you have to limit your social activities because of your fatigue? & 2 & 3.53 \\
\hline FATIMP42 & How often were you less effective at home due to your fatigue? & 2 & 3.52 \\
\hline FATIMP5 & $\begin{array}{l}\text { How often were you less effective at work due to your fatigue } \\
\text { (include work at home)? }\end{array}$ & 2 & 3.52 \\
\hline FATIMP55 & How often did you have to force yourself to get up and do things because of your fatigue? & 2 & 3.51 \\
\hline FATIMP19 & How often were you too tired to do your household chores? & 2 & 3.41 \\
\hline AN4 & I have trouble $<\mathrm{U}>$ finishing $</ \mathrm{U}>$ things because I am tired & 1 & 3.40 \\
\hline FATIMP34 & To what degree did you have to limit your social activities because of your fatigue? & 1 & 3.29 \\
\hline FATIMP45 & To what degree did your fatigue interfere with your ability to engage in recreational activities? & 1 & 3.24 \\
\hline FATIMP26 & How often were you too tired to socialize with your family? & 2 & 3.11 \\
\hline FATIMP29 & How often were you too tired to leave the house? & 2 & 3.09 \\
\hline
\end{tabular}


Table 3 (continued)

\begin{tabular}{llcc}
\hline Item & Item Stem & $\begin{array}{c}\text { Responses Scale* } \\
\text { Discrimination } \\
\text { Parameter Value }\end{array}$ & 2.87 \\
\hline FATIMP56 & How often were you too tired to socialize with your friends? & 2 & 2.84 \\
FATIMP25 & How often was it an effort to carry on a conversation because of your fatigue? & 1 & 1 \\
FATIMP28 & How hard was it for you to carry on a conversation because of your fatigue? & 1 & 2.81 \\
AN7 & I am able to do my usual activities & 1 & 2.31 \\
AN12 & I am too tired to eat & 2 & 2.31 \\
AN14 & I need help doing my usual activities & 2 & 2.11 \\
FATIMP21 & How often were you too tired to take a bath or shower? & 1.70 \\
FATIMP8 & How often were you too tired to watch television? &
\end{tabular}

*Response scale 1 : 1 , not at all; 2 , a little bit; 3 , somewhat; 4 , quite a bit; 5 , very much

Response scale 2: 1 , never; 2, rarely; 3 , sometimes; 4, often; 5 , always

Response scale 3: 1 , none; 2 , mild; 3 , moderate; 4 , severe; 5 , very severe

Response scale 4: 1 , none; 2,1 day; 3, 2-3 days; 4, 4-5 days; 5, 6-7 days

Fig. 1 Research Assessment and Clinical Tool-Fatigue (ReACT-F). To obtain permission to use, please contact the corresponding author

(C) K. Dickinson, D. Lynch Kelly, JS. Lai, L. Saligan

\section{Research Assessment and Clinical Tool-Fatigue (ReACT-F)}

In, the past 7 days, what has been your average level fatigue on a scale of $0-10$, with zero being no fatigue and 10 being the worst fatigue possible.

\begin{tabular}{c|c|c|c|c|c|c|c|c|c|c|c}
$\mathbf{0}$ & $\mathbf{1}$ & $\mathbf{2}$ & $\mathbf{3}$ & $\mathbf{4}$ & $\mathbf{5}$ & $\mathbf{6}$ & $\mathbf{7}$ & $\mathbf{8}$ & $\mathbf{9}$ & $\mathbf{1 0}$ \\
$\begin{array}{c}\text { Worst } \\
\text { Natigue }\end{array}$ & \\
Fatigue
\end{tabular}

atigue

In the past 7 days:

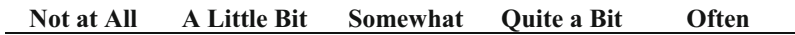

1. How run-down did you feel on average?

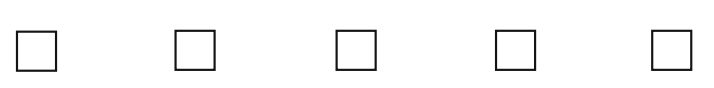

2. To what degree did your fatigue interfere with your physical functioning?

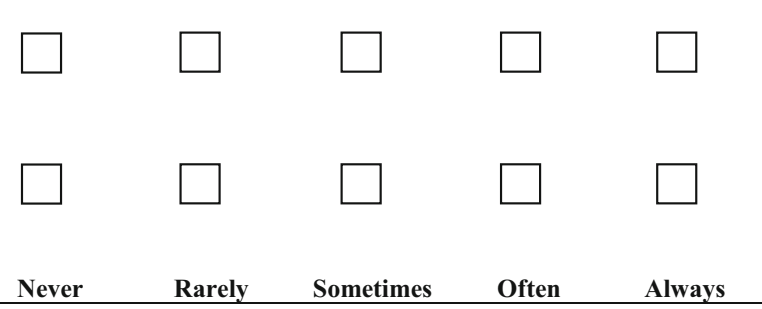

4. How often did your fatigue make you feel less alert?

5. How often did you have to push yourself to get things done because of your fatigue?

3. I am frustrated by being too tired to do the things I want to do.

PROMIS Short Form- Fatigue 
within the global fatigue construct. The ReACT-F tool can assist in identifying clinical and demographic attributes, as well as the biologic profile of the specific fatigue experience, to advance our understanding of the etiology of CRF. Understanding the etiology of CRF is important for treatment development and generation of algorithms to identify individuals at risk to develop clinically meaningful fatigue related to the progression of their disease or as a side effect of their treatment.

\section{Limitations}

The five items have high discriminative value demonstrating the ability to allow for the assessment of multidimensions of fatigue; however, they did not have sufficient power when factor loading to be independent from the construct of fatigue, as assessed through comparison of factor loadings between the general factor (fatigue) and the local (subdomain) factors. Thus, the dimensions are not independent constructs, but components of a general fatigue construct.

\section{Conclusions}

In conclusion, the ReACT-F is a CRF-specific self-report short form that addresses the need for a brief, clinically useful tool to quickly assess the multidimensional nature of CRF. The ReACT-F assesses five common dimensions of CRF as well as perceived burden of the fatigue dimensions. This tool has clinical and scientific promise, to advance our understanding and management of CRF. We anticipate that the ReACT-F can be completed in the clinical setting in approximately $3 \mathrm{mi}-$ nutes, providing clinicians with meaningful data to drive personalized interventions. Further validation of the ReACT-F is highly encouraged to assess its psychometric properties and determine its clinical utility.

Acknowledgements This work is fully supported by the Division of Intramural Research of the National Institute of Nursing Research of the NIH, Bethesda, Maryland. Dr. Lai's efforts were supported by a grant from the National Cancer Institute (1U2CCA186878; PI: Cella)

\section{Compliance with ethical standards}

The data used in this publication are publicly available on the "HealthMeasures Dataverse." "HealthMeasures Dataverse" is a repository of data from self-reported patient assessments evaluating symptoms, well-being, and life satisfaction; physical, mental, and social health; as well as examiner-administered assessments measuring sensory, motor, and cognitive functions. Data from NIH-funded initiatives include PROMIS®, NIH Toolbox, Neuro-QoL, and ASCQ-Me.

Conflict of interest The authors declare that they have no conflict of interest.
Open Access This article is distributed under the terms of the Creative Commons Attribution 4.0 International License (http:// creativecommons.org/licenses/by/4.0/), which permits unrestricted use, distribution, and reproduction in any medium, provided you give appropriate credit to the original author(s) and the source, provide a link to the Creative Commons license, and indicate if changes were made.

Publisher's note Springer Nature remains neutral with regard to jurisdictional claims in published maps and institutional affiliations.

\section{References}

1. Berger AM, Mitchell SA, Jacobsen PB, Pirl WF (2015) Screening, evaluation, and management of cancer-related fatigue: ready for implementation to practice? CA Cancer J Clin 65:190-211. https://doi.org/10.3322/caac. 21268

2. Filler K, Saligan LN (2016) Defining cancer-related for biomarker discovery. Support Care Cancer 24:5-7. https://doi.org/10.1007/ s00520-015-2965-5

3. National Comprehensive Cancer Network (NCCN) Clinical Practice Guidelines in Oncology (2018) Cancer-related fatigue, version 2.2018. Available from URL: https://www.ncen.org/ professionals/physician_gls/pdf/fatigue.pdf. Accessed Jun 4, 2018

4. National Cancer Institute (2017) Fatigue (PDQ®)-health professional version. Available from URL: https://www.cancer.gov/ about-cancer/treatment/side-effects/fatigue/fatigue-hp-pdq. Accessed Jun 4, 2018

5. Howell D, Keshavarz H, Broadfield L, et al. on behalf of the Cancer Journey Advisory Group of the Canadian Partnership Against Cancer. A Pan Canadian Practice Guideline for Screening, Assessment, and Management of Cancer-Related Fatigue in Adults Version 2-2015, Toronto: Canadian Partnership Against Cancer (Cancer Journey Advisory Group) and the Canadian Association of Psychosocial Oncology, April 2015. Available from URL: https://www.capo.ca/pdf/CRF_Guideline.pdf. Accessed Jun 4, 2018

6. Bower J, Bak K, Berger A et al (2014) Screening, assessment, and management of fatigue in adult survivors of cancer: an American Society of Clinical Oncology clinical practice guideline adaptation. J Clin Oncol 32:1840-1850. https://doi.org/10.1200/JCO.2013.53. 4495

7. Jean-Pierre P, Figueroa-Moseley CD, Kohli S, Fiscella K, Palesh OG, Morrow GR (2007) Assessment of cancer-related fatigue: implications for clinical diagnosis and treatment. Oncologist 12(Suppl 1):11-21

8. Strasser F, Müller-Käser I, Dietrich D (2009) Evaluating cognitive, emotional, and physical fatigue domains in daily practice by singleitem questions in patients with advanced cancer: a cross-sectional pragmatic study. J Pain Symptom Manag 38:505-514. https://doi. org/10.1016/j.jpainsymman.2008.12.009

9. Minton O, Stone P (2009) A systematic review of the scales used for the measurement of cancer-related fatigue (CRF). Ann Oncol 20:17-25. https://doi.org/10.1093/annonc/mdn537

10. Lai JS, Cella D, Choi S et al (2011) How item banks and their application can influence measurement practice in rehabilitation medicine: a PROMIS Fatigue item bank example. Arch Phys Med Rehabil 92(Suppl 10):S20-S27. https://doi.org/10.1016/j. apmr.2010.08.033

11. Cella D, Riley W, Stone AA, Rothrock N, Reeve B, Yount S, Amtmann D, Bode R, Buysse D, Choi S, Cook K, Devellis R, DeWalt D, Fries JF, Gershon R, Hahn EA, Lai JS, Pilkonis P, Revicki D, Rose M, Weinfurt K, Hays R, PROMIS Cooperative 
Group (2010) The Patient Reported Outcomes Measurement Information System (PROMIS) developed and tested its first wave of adult self-reported health outcome item banks: 2005-2008. J Clin Epidemiol 63:1179-1194. https://doi.org/10.1016/j.jclinepi.2010. 04.011

12. Junghaenel DU, Christodoulou C, Lai JS, Stone AA (2011) Demographic correlates of fatigue in the US general population: results from the Patient-Reported Outcomes Measurement Information System (PROMIS) initiative. J Psychosom Res 71: 117-123. https://doi.org/10.1016/j.jpsychores.2011.04.007

13. Garcia SF, Cella D, Clauser SB, Flynn KE, Lad T, Lai JS, Reeve BB, Wilder Smith A, Stone AA, Weinfurt K (2007) Standardizing patient-reported outcomes assessment in cancer clinical trials: a PROMIS initiative. J Clin Oncol 25:5106-5112

14. Ameringer S, Elswick RK Jr, Menzies V, Robins JL, Starkweather A, Walter J, Gentry AE, Jallo N (2016) Psychometric evaluation of the PROMIS Fatigue-short form across diverse populations. Nurs Res 65:279-289. https://doi.org/10.1097/NNR. 000000000000162

15. Cook KF, Bamer AM, Roddey TS, Kraft GH, Kim J, Amtmann D (2012) A PROMIS Fatigue short form for use by individuals who have multiple sclerosis. Qual Life Res 21:1021-1030. https://doi. org/10.1007/s11136-011-0011-8

16. Elbers RG, Rietberg MB, van Wegen EE et al (2012) Self-report fatigue questionnaires in multiple sclerosis, Parkinson's disease and stroke: a systematic review of measurement properties. Qual Life Res 21:925-944. https://doi.org/10.1007/s11136-011-0009-2

17. Dittner AJ, Wessely SC, Brown RG (2004) The assessment of fatigue: a practical guide for clinicians and researchers. J Psychosom Res 56:157-170

18. Hewlett S, Dures E, Almeida C (2011) Measures of fatigue: Bristol Rheumatoid Arthritis Fatigue Multi-Dimensional Questionnaire (BRAF MDQ), Bristol Rheumatoid Arthritis Fatigue Numerical Rating Scales (BRAF NRS) for severity, effect, and coping, Chalder Fatigue Questionnaire (CFQ), Checklist Individual Strength (CIS20R and CIS8R), Fatigue Severity Scale (FSS), Functional Assessment Chronic Illness Therapy (Fatigue)
(FACIT-F), Multi-Dimensional Assessment of Fatigue (MAF), Multi-Dimensional Fatigue Inventory (MFI), Pediatric Quality Of Life (PedsQL) Multi-Dimensional Fatigue Scale, Profile of Fatigue (ProF), Short Form 36 Vitality Subscale (SF-36 VT), and visual analog scales (VAS). Arthritis Care Res (Hoboken) 63(suppl 11): S263-S286. https://doi.org/10.1002/acr.20579

19. Seyidova-Khoshknabi D, Davis MP, Walsh D (2011) A systematic review of cancer-related fatigue measurement questionnaires. Am J Hosp Palliat Care 28:119-129. https://doi.org/10.1177/ 1049909110381590

20. Shahid A, Shen J, Shapiro CM (2010) Measurements of sleepiness and fatigue. J Psychosom Res 69:81-89. https://doi.org/10.1016/j. jpsychores.2010.04.001

21. Whitehead L (2009) The measurement of fatigue in chronic illness: a systematic review of unidimensional and multidimensional fatigue measures. J Pain Symptom Manag 37:107-128. https://doi. org/10.1016/j.jpainsymman.2007.08.019

22. McDonald RP (1999) Test theory: a unified treatment. Lawrence Earlbaum Associates, Inc., Mahwah, NJ, pp 142-145

23. Gibbons R, Hedeker D (1992) Full-information item bi-factor analysis. Psychometrika 57:423-436

24. Lai JS, Crane PK, Cella D (2006) Factor analysis techniques for assessing sufficient unidimensionality of cancer related fatigue. Qual Life Res 15:1179-1190

25. Lai JS, Butt Z, Wagner L, Sweet JJ, Beaumont JL, Vardy J, Jacobsen PB, Shapiro PJ, Jacobs SR, Cella D (2009) Evaluating the dimensionality of perceived cognitive function. J Pain Symptom Manag 37:982-995. https://doi.org/10.1016/j. jpainsymman.2008.07.012

26. Lai JS, Cella D, Crane P (2005) Cancer related fatigue is sufficiently unidimensional for applications requiring unidimensionality. Qual Life Res 14:1990

27. Patient-Reported Outcomes Measurement Information System (PROMIS) (2018) Fatigue: a brief guide to the PROMIS® Fatigue instruments. Available from URL: http://www. healthmeasures.net/images/PROMIS/manuals/PROMIS_Fatigue Scoring_Manual.pdf. Accessed Jun 10, 2018 